\title{
Risk Factors Associated with Pain Severity in Patients with Non-specific Low Back Pain in Southern China
}

\author{
Shilabant Sen Sribastav ${ }^{1, *}$, Jun Long ${ }^{1,{ }^{*}}$, Peiheng $\mathrm{He}^{1}$, Wei He ${ }^{2}$, Fubiao $\mathrm{Ye}^{1}$, \\ Zemin $\mathrm{Li}^{1}$, Jianru Wang ${ }^{1}$, Hui Liu ${ }^{1}$, Hua Wang ${ }^{1}$, Zhaomin Zheng ${ }^{1,3}$ \\ ${ }^{I}$ Department of Orthopaedics, First Affiliated Hospital of Sun Yat-sen University, Guangzhou, China \\ ${ }^{2}$ Department of Orthopaedics, Jinshazhou Hospital of Guangzhou University of Chinese Medicine, Guangzhou, China \\ ${ }^{3}$ Pain Research Center and Department of Physiology, Zhongshan Medical School of Sun Yat-sen University, Guangzhou, China
}

Study Design: A prospective cross-sectional study.

Purpose: To evaluate the risk factors associated with the severity of pain intensity in patients with non-specific low back pain (NSLBP) in Southern China.

Overview of Literature: Low back pain (LBP) is the leading cause of activity limitation and work absence throughout the world, so a firm understanding of the risk factor associated with NSLBP can provide early and prompt interventions that are aimed at attaining long-term results.

Methods: Participants were recruited from January 2014 to January 2016 and were surveyed using a self-designed questionnaire. Anonymous assessments included Short Form 36-Item Health Survey (SF-36) and Visual Analogue Scale (VAS). The association between the severity of NSLBP and these potential risk factors were evaluated.

Results: A total of 1,046 NSLBP patients were enrolled. The patients with primary school education, high body mass index (BMI), those exposed to sustained durations of driving and sitting, smoking, recurrent LBP had increased VAS and Oswestry Disability Index (ODI) scores with lower SF-36 scores $(p<0.01)$. Workers and drivers compared with waiters and patients who lifted $>10 \mathrm{~kg}$ objects in a quarter of their work time for $>10$ years had higher VAS and ODI scores with lower SF-36 scores $(p<0.01)$. Multiple logistic regression showed lower levels of education, LBP for 1-7 days, long-lasting LBP in last year, smoking, long duration driving, and higher BMI were associated with more severe VAS score.

Conclusions: The severity of NSLBP is associated with lower levels of education, poor standards of living, heavy physical labor, long duration driving, and sedentary lifestyle. Patients with recurrent NSLBP have more severe pain. Reducing rates of obesity, the duration of heavy physical work, driving or riding, and attenuating the prevalence of sedentary lifestyles and smoking may reduce the prevalence of NSLBP.

Keywords: Low back pain; Risk factors; Visual Analogue Scale; Medical outcomes study; Short Form 36-Item Health Survey

Received Aug 9, 2017; Revised Oct 16, 2017; Accepted Oct 26, 2017

Co-corresponding author: Hua Wang

Department of Orthopaedic Surgery, First Affiliated Hospital of Sun Yat-sen University, 58 Zhongshan Second Road, Guangzhou, P.R. 510080, China Tel: +86-20-87331675, Fax:+86-20-87333601, E-mail: wangxucheng@gmail.com

Zhaomin Zheng

Department of Orthopaedic Surgery, First Affiliated Hospital of Sun Yat-sen University, 58 Zhongshan Second Road, Guangzhou, P.R. 510080, China Tel: +86-20-87331675, Fax: +86-20-87333601, E-mail: zhengzm1@163.com

*These two authors contributed equally to this work. 


\section{Introduction}

Low back pain (LBP) is the leading cause of activity limitation and work absence throughout the world with the lifetime prevalence reported as high as $83 \%$ and the point prevalence ranging from $19 \%$ to $39 \%$ [1]. LBP causes an enormous economic burden on individuals, families, and communities [1]. LBP without specific pathology such as a tumor, fracture and inflammation is known as nonspecific low back pain (NSLBP), which accounts for $>85 \%$ of all LBPs [2]. Thus, a firm understanding of the risk factor associated with NSLBP can provide early and prompt interventions that are aimed at attaining long-term results.

LBP is associated with multiple risk factors, including individual (e.g., gender, age, lifestyle, physical capacity, and body weight) [3], psychosocial (e.g., anxiety, depression, social support, and job satisfaction) [4], and physical factors(e.g., hard manual work, heavy weight lifting, bending down or twisting, etc.) [5]. However, Kwon et al. [5] showed that the development of LBP was not dependent on obesity, smoking, or stress level. Previous reviews suggest that longer sitting duration [6], standing, and walking [7], body bending and twisting [8], and heavy lifting [9] were not independent causes of LBP, and the role of these risk factors is still controversial. Furthermore, previous investigations did not exclude specific pathologies (e.g., infection, tumor, osteoporosis, fracture, structural deformity, an inflammatory disorder, and radicular pain), which can influence the results [10].

In general, although many studies have evaluated the risk factors for LBP, the results were varied and often conflicting with only a few studies focused on NSLBP [2]. Therefore, the purpose of this investigation was to further identify the risk factors associated with enhanced NSLBP, particularly in South China.

\section{Materials and Methods}

\section{Design and subjects}

The study was a cross-sectional self-assessment questionnaire survey, which collected information about NSLBP and personal and physical factors. The characteristics of the participants in each group are summarized in Table 1.

The patients whose leading complaint was LBP for $>1$ week, those who agreed to undergo magnetic resonance imaging (MRI) examination, and those with occupations involving physical labor, office work, including restaurant waiters and drivers, were included in the present study. The MRI examination was performed for all the enrolled NSLBP patients to eliminate the presence of specific spine pathology such as a tumor, fracture, and inflammation.

Individuals aged $<18$ years or $>65$ years and with mental disorders and a history of cancer or severe chronic physical disorders (e.g., hypertension, diabetes, coronary heart disease, chronic kidney disease, bronchitis, and asthma) were excluded from the study. Participants with LBP that was attributed to spine fractures, spine inflammation, spinal tumor, spinal tuberculosis, lumbar disc herniation, spinal stenosis, spondylolisthesis, aneurysm, or lithiasis were also excluded.

A pretested, self-administered, structured questionnaire was used for data collection. The survey examined demographic data, gender, age, weight, height, smoking habits, drinking habits, marital status, history of LBP in the last year, the duration of the last LBP, pain consultation at a hospital, history of LBP treatment in the last year, current occupation, history of heavy physical labor, duration of driving or riding, history of exercise, duration of sitting, and duration of standing. For good validity and reliability, Visual Analogue Scale (VAS), 36-Item Short Form Health Survey (SF-36), and Oswestry Disability Index (ODI) were used to evaluate the severity of LBP and quality of life.

\section{Analysis}

Numerical variables are expressed as the mean and standard deviation. Initially, the simple descriptive analysis was performed, and comparisons between the respondents were conducted using a Student $t$-test and a chisquare test or a simple logistic regression model for other categorical variables. The factors which were significantly associated $(p<0.05)$ with LBP in univariate analysis were further analyzed in multiple logistic regression analysis. Odds ratios (ORs) were calculated indicating the relative odds of occurrence of LBP due to the presence of a particular factor.

\section{Ethical issues}

All patients who participated in the study were informed about the purpose of the study, and voluntary consent was obtained. The study was approved by Ethics Committee of 

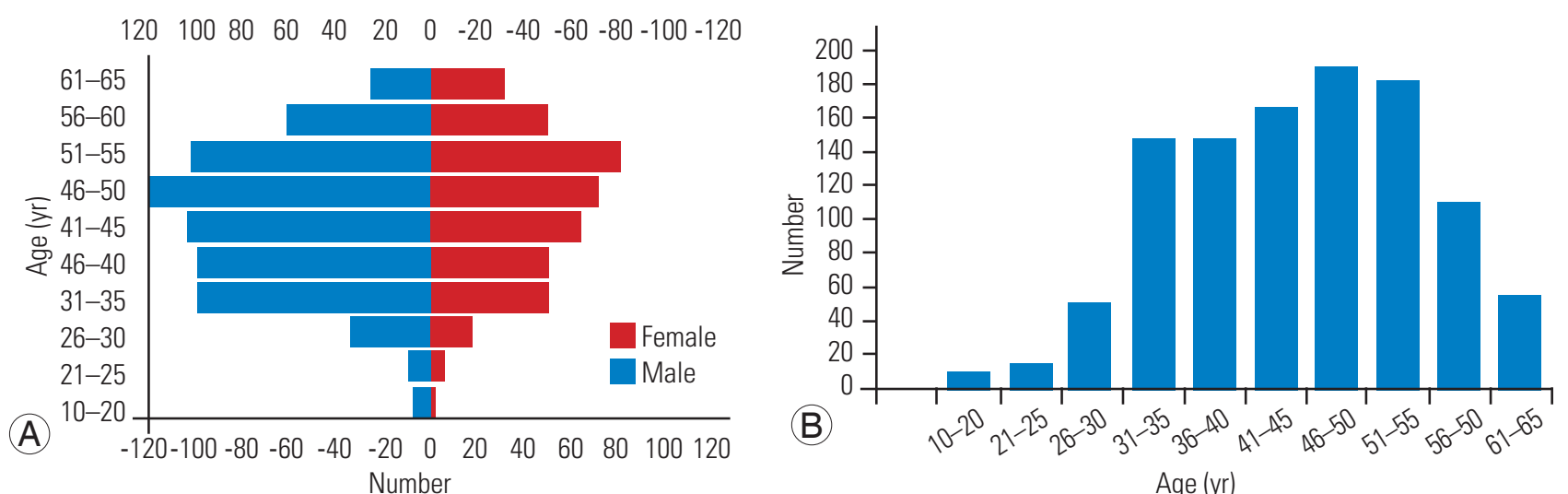

Fig. 1. (A, B) Age structure distribution map showed the age of the non-specific low back pain occurrence is mainly concentrated in the age group of $31-55$ years.

the First Affiliated Hospital of Sun Yat-sen University (approval no., 2011-196).

\section{Results}

\section{Demographic characteristics}

A total of 1,046 NSLBP patients were enrolled from January 2014 to January 2016 (621 males and 425 females). The average age was $37.22 \pm 11.46$ years (range, $16-62$ years) (Fig. 1); the average height, weight, and body mass index (BMI) were $160 \pm 12 \mathrm{~cm}$ (range, 135-189 cm), 62.77 \pm 11.93 $\mathrm{kg}$ (range, $37.0-110.0 \mathrm{~kg}$ ), and $24.65 \pm 5.21 \mathrm{~kg} / \mathrm{m}^{2}$ (range, $15.1-39.44 \mathrm{~kg} / \mathrm{m}^{2}$ ), respectively. The average VAS, average ODI, and average SF-36 scores for LBP were $4.50 \pm 1.81$ points, $38.06 \pm 17.65$, and $65.41 \pm 20.64$, respectively. The SF-36 score was divided into physiological functions, 69.19 \pm 20.30 ; role physiological functions, 51.94 \pm 30.67 ; bodily pain, $60.27 \pm 22.34$; general health, $66.83 \pm 20.10$; vitality, 68.46 \pm 19.55 ; social function, $64.76 \pm 24.14$; roleemotional, 61.01 \pm 80.70 ; and mental health, $67.61 \pm 18.87$ (Table 1).

\section{Risk factors associated with low back pain}

The factors associated with LBP were separated into demographic factors and workplace/employment factors. The demographic factors such as age and gender showed no significant association with LBP in our study $(p>0.05)$ (Table 2).

The patients with primary school education demonstrated more severe LBP than those who had completed secondary- or university-level education $(p<0.01)$; ad- ditionally, the patients with secondary-level education had higher levels of LBP than those with university-level education, but the difference was not significant $(p>0.05)$ (Table 3). We then analyzed the effect of occupation on LBP for the four careers. The results showed that there was a significant difference in pain intensity between the physical workers and waiters groups and the drivers and waiters groups $(p<0.01)$. The waiters group had the lowest LBP VAS score, whereas the heavy workers had the highest score (Table 3). The patients with a higher BMI demonstrated more severe LBP when compared with those with normal BMI and had a higher VAS score $(p<0.05)$, higher ODI score, and lower SF-36 life quality score (Table 3).

The patients who lifted objects $>10 \mathrm{~kg}$ in at least one quarter of their total work time for $>10$ years had more serious LBP when compared with those who did not lift heavy weights $(p=0.006)$; they had a higher ODI score $(p<0.001)$ and lower SF-36 score $(p<0.001)$. Prolonged driving numerically increased the degree of LBP VAS score $(p=0.037)$ with increased ODI score $(p=0.019)$ and decreased SF-36 score (Table 2). The patients who sat for $>8 /$ day had a higher LBP VAS score $(p=0.023)$, higher ODI score $(p=0.172)$, and lower SF-36 score $(p=0.156)$ (Table 2).

The patients who stood for $>8$ /day had a lower LBP VAS score $(p=0.232)$, lower ODI score $(p=0.572)$, and higher SF-36 score $(p=0.054)$, but the difference was not statistically significant (Table 2 ). The patients who regularly exercised had a better quality of life but no effect on pain reduction, had a similar VAS score $(p=0.249)$, similar ODI score $(p=0.707)$, and higher SF-36 score $(p=0.001)$ (Table $2)$. Smokers had more severe LBP than the non-smokers, a 
Table 1. Demographic characteristics $(N=1,046)$

\begin{tabular}{|c|c|c|c|c|c|}
\hline \multirow{2}{*}{ Characteristic } & \multirow{2}{*}{ Sub-group } & \multicolumn{2}{|c|}{ Gender } & \multirow{2}{*}{$\chi^{2}$} & \multirow{2}{*}{$p$-value } \\
\hline & & Male & Female & & \\
\hline No. of patients & & $621(59.4)$ & $425(40.6)$ & & \\
\hline Age (yr) & & $44.82 \pm 9.75$ & $46.20 \pm 10.06$ & & 0.207 \\
\hline Height (m) & & $1.60 \pm 0.12$ & $1.55 \pm 0.10$ & & 0.286 \\
\hline Weight (kg) & & $63.08 \pm 11.66$ & $57.57 \pm 10.76$ & & 0.312 \\
\hline \multirow[t]{4}{*}{ Body mass index $\left(\mathrm{kg} / \mathrm{m}^{2}\right)$} & & $24.90 \pm 5.30$ & $24.29 \pm 5.27$ & & 0.229 \\
\hline & Normal & $324(59.4)$ & $241(59.4)$ & 3.02 & 0.221 \\
\hline & Overweight & $152(59.4)$ & $98(59.4)$ & & \\
\hline & Obese & 145 (59.4) & $86(59.4)$ & & \\
\hline \multirow[t]{2}{*}{ Smoking } & Yes & $108(17.4)$ & $35(8.2)$ & 12.84 & $<0.01$ \\
\hline & No & $513(82.6)$ & $390(91.8)$ & & \\
\hline \multirow[t]{2}{*}{ Drinking } & Yes & $112(18.0)$ & $15(3.5)$ & 30.7 & $<0.01$ \\
\hline & No & $509(82.0)$ & $410(96.5)$ & & \\
\hline \multirow[t]{3}{*}{ Education level } & Primary school & $189(30.4)$ & $133(31.3)$ & 0.299 & 0.861 \\
\hline & Middle school & $331(53.3)$ & $228(53.6)$ & & \\
\hline & University & $101(16.3)$ & $64(15.1)$ & & \\
\hline \multirow[t]{3}{*}{ Duration of current LBP (day) } & $1-7$ & $199(32.0)$ & $137(32.2)$ & 1.38 & 0.501 \\
\hline & $8-30$ & $227(36.6)$ & $142(33.4)$ & & \\
\hline & $>30$ & $195(31.4)$ & $146(34.3)$ & & \\
\hline \multirow[t]{2}{*}{ LBP last year } & Yes & $300(48.3)$ & $185(43.5)$ & 2.32 & 0.130 \\
\hline & No & $321(51.7)$ & $240(56.5)$ & & \\
\hline \multirow[t]{3}{*}{ Duration of LBP in last year (day) } & $1-7$ & $98(32.6)$ & $58(31.4)$ & 21.8 & $<0.01$ \\
\hline & $8-30$ & $113(37.7)$ & $68(36.7)$ & & \\
\hline & $>30$ & $89(29.7)$ & $59(31.9)$ & & \\
\hline \multirow[t]{2}{*}{ Pain consultation in last year } & Yes & $135(21.7)$ & $93(21.9)$ & 0.003 & $>0.05$ \\
\hline & No & 486 (78.3) & $332(79.1)$ & & \\
\hline \multirow[t]{4}{*}{ Occupation } & Heavy worker & $265(42.7)$ & $72(16.9)$ & 271.3 & $<0.01$ \\
\hline & Office staff & $248(39.9)$ & $136(32.0)$ & & \\
\hline & Waiter & $46(7.4)$ & $212(49.9)$ & & \\
\hline & Driver & $62(10.0)$ & $5(11.2)$ & & \\
\hline \multirow[t]{2}{*}{ Heavy physical labor during work } & Yes & $37(6.0)$ & $2(0.4)$ & 76.6 & $<0.01$ \\
\hline & No & $584(94.0)$ & $423(99.6)$ & & \\
\hline \multirow[t]{2}{*}{ Long time driving or taking bus/subway } & Yes & $156(25.1)$ & $64(15.1)$ & 15.4 & $<0.01$ \\
\hline & No & $465(74.9)$ & $361(84.9)$ & & \\
\hline \multirow[t]{2}{*}{ Regular exercise } & Yes & $38(6.1)$ & $26(6.1)$ & 0.37 & 0.590 \\
\hline & No & $583(93.9)$ & 399 (93.9) & & \\
\hline \multirow[t]{2}{*}{ Long time sitting } & Yes & $221(35.6)$ & $94(22.1)$ & 21.8 & $<0.01$ \\
\hline & No & $400(64.4)$ & $331(87.9)$ & & \\
\hline \multirow[t]{2}{*}{ Long time standing } & Yes & $80(12.9)$ & $175(41.2)$ & 109.6 & $<0.01$ \\
\hline & No & $541(87.1)$ & $250(58.8)$ & & \\
\hline Visual Analogue Scale score & & $4.54 \pm 1.75$ & $4.45 \pm 1.88$ & & 0.458 \\
\hline
\end{tabular}


Table 1. Continued

\begin{tabular}{|c|c|c|c|c|}
\hline \multirow{2}{*}{ Characteristic } & \multirow{2}{*}{ Sub-group } & \multicolumn{2}{|c|}{ Gender } & \multirow{2}{*}{$p$-value } \\
\hline & & Male & Female & \\
\hline Oswestry Disability Index score & & $38.53 \pm 17.22$ & $37.37 \pm 18.27$ & 0.296 \\
\hline \multirow[t]{9}{*}{ 36-Item Short Form Health Survey score } & Physical component score & $64.74 \pm 17.78$ & $65.63 \pm 24.90$ & 0.160 \\
\hline & Physical function & $69.14 \pm 19.76$ & $69.27 \pm 21.08$ & $>0.05$ \\
\hline & Role-physical & $51.73 \pm 30.49$ & $52.24 \pm 30.97$ & \\
\hline & Body pain & $60.18 \pm 21.90$ & $60.39 \pm 22.98$ & \\
\hline & General health & $67.57 \pm 19.30$ & $65.74 \pm 21.19$ & \\
\hline & Vitality & $68.58 \pm 19.19$ & $68.27 \pm 20.09$ & \\
\hline & Social functioning & $64.42 \pm 24.04$ & $65.26 \pm 24.30$ & \\
\hline & Role-emotional & $57.90 \pm 32.96$ & $65.56 \pm 120.12$ & \\
\hline & Mental health & $68.15 \pm 18.08$ & $66.83 \pm 19.95$ & \\
\hline
\end{tabular}

Values are presented as number (\%) or mean \pm standard deviation. LBP, low back pain.

higher VAS score $(p<0.001)$, a higher ODI score $(p<0.001)$, and a lower SF-36 score $(p<0.001)$ (Table 2$)$.

There was no significant correlation between alcohol consumption and severity of LBP with VAS score $(p=0.783)$, ODI score $(p=0.561)$, and SF-36 score $(p=0.162)$. The recurrent LBP patients had a higher VAS score $(p<0.01)$, higher ODI score $(p<0.01)$, and lower SF36 score $(p<0.01)$ when compared with those of the new LBP patients (Table 2).

Further analysis found that the severity of current LBP increased with the duration of the last LBP and had a higher VAS score $(p<0.05)$, higher ODI score $(p<0.05)$, and lower SF-36 score $(p<0.05)$ (Table 3$)$.

In the multiple logistic regression models, all predictive variables were significant after controlling for age, gender, and the other variables. Lower levels of education, the duration of current LBP for 1-7 days, long duration of LBP in the last year, smoking (OR, 1.634; 95\% confidence interval [CI], 1.136-2.350), long driving duration (OR, 1.642; 95\% CI, 1.170-2.304), and higher BMI scores were associated with more severe NSLBP VAS score; particularly, primary school (OR, 2.701; 95\% CI, 1.999-3.649) compared with middle school, primary school (OR, 4.229; 95\% CI, 2.602-6.874) compared with university, current LBP for 1-7 days (OR, 1.994; 95\% CI, 1.473-2.701) compared with 8-30 days, current LBP 1-7 days (OR, 2.358; 95\% CI, 1.728-3.219) compared with $>30$ days, last year LBP 0 day (OR, 1.840; 95\% CI, 1.308-2.589) compared with 8-30 days, last year LBP 0 day (OR, 4.436; 95\% CI, $3.010-6.537)$ compared with $>30$ days, heavy worker (OR, 2.052; 95\% CI, 1.407-2.994) compared with waiter, over weight individuals (OR, 1.473; 95\% CI, 1.081-2.008) compared with normal weight individuals, obese subjects (OR, 2.321; 95\% CI, 1.675-3.217) compared with normal weight subjects (Table 4).

\section{Discussion}

\section{Principal findings}

This descriptive, cross-sectional, and self-administered questionnaire-based study in Southern Chinese NSLBP patients revealed that smoking, increased BMI, heavy physical labor, prolonged sitting, history of LBP, and long duratoins of driving are risk factors for increased pain intensity in the NSLBP patients.

Age is one of the most common risk factors for LBP. The cross-sectional data demonstrated that initial onset of LBP commonly occurs around the age of 30 years, overall prevalence increases with age until 60-65 years, and then gradually declines. In this study, NSLBP mainly concentrated in patients aged 31-55 years. We excluded people who were aged $>65$ years, who typically presented multiple comorbidities, and who were often afflicted with spinal stenosis. 


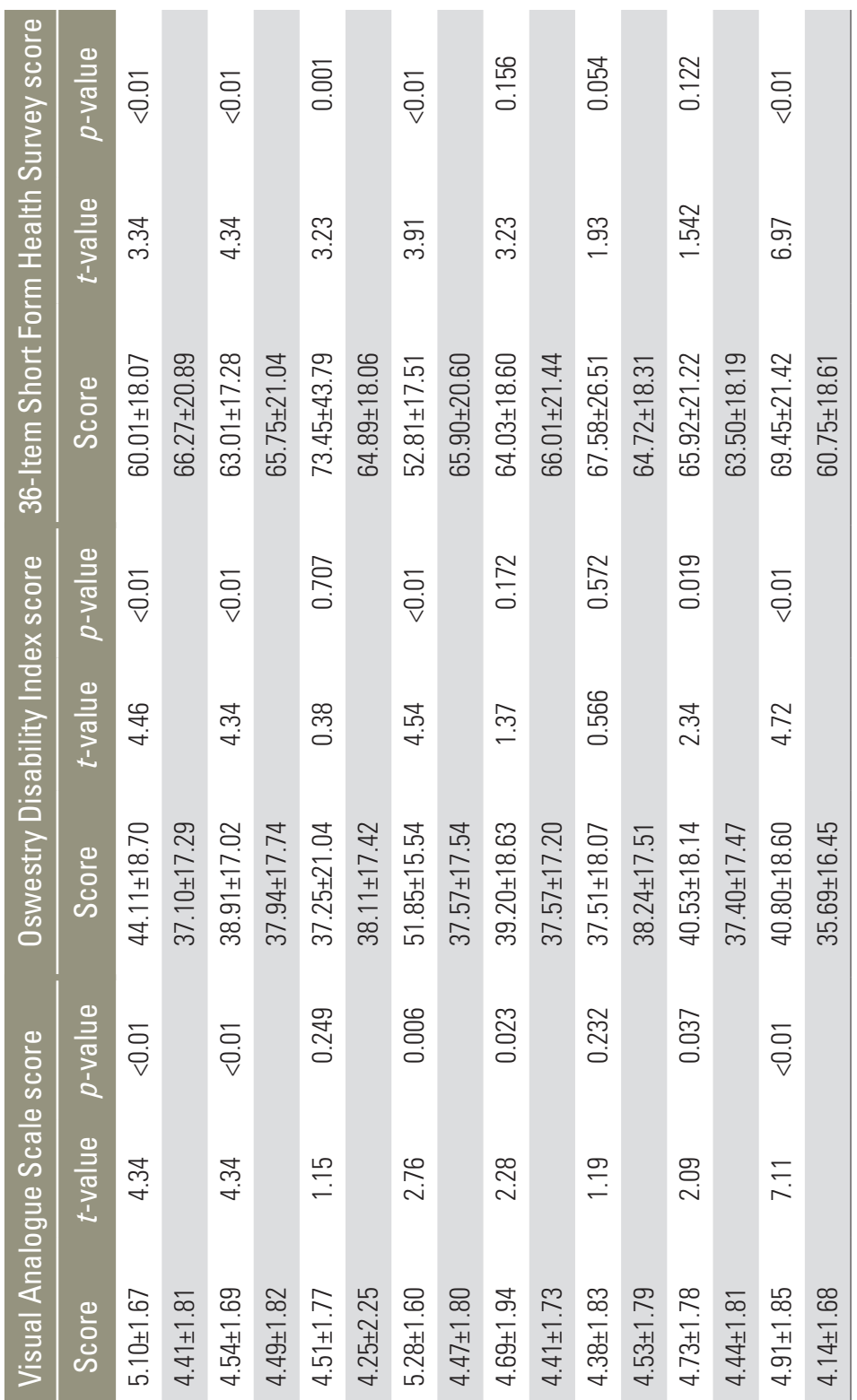
家

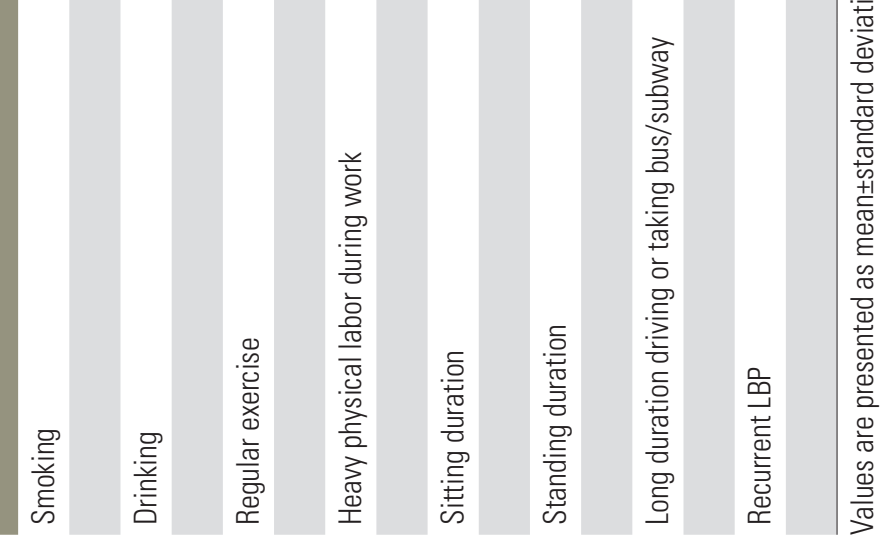


Table 3. Risk factors associated with non-specific low back pain

\begin{tabular}{|c|c|c|c|c|c|c|c|c|}
\hline \multirow[t]{2}{*}{ Characteristic } & \multirow[t]{2}{*}{ Sub-group } & \multirow{2}{*}{ No. } & \multicolumn{2}{|c|}{$\begin{array}{l}\text { Visual Analogue } \\
\text { Scale score }\end{array}$} & \multicolumn{2}{|c|}{$\begin{array}{l}\text { Oswestry Disability } \\
\text { Index score }\end{array}$} & \multicolumn{2}{|c|}{$\begin{array}{l}\text { 36-Item Short Form } \\
\text { Health Survey score }\end{array}$} \\
\hline & & & Score & $p$-value & Score & $p$-value & Score & $p$-value \\
\hline \multirow[t]{3}{*}{ Education level } & Primary school (I) & 189 & $5.27 \pm 1.79$ & $<0.01$ & $43.87 \pm 18.10$ & $<0.01$ & $58.32 \pm 18.83$ & $<0.01$ \\
\hline & Middle school (II) & 331 & $4.22 \pm 1.67^{a)}$ & & $36.14 \pm 16.60^{\mathrm{a})}$ & & $68.21 \pm 21.24^{a)}$ & \\
\hline & University (III) & 101 & $3.94 \pm 1.78^{b)}$ & & $33.24 \pm 17.40^{b)}$ & & $69.77 \pm 18.40^{b)}$ & \\
\hline \multirow[t]{4}{*}{ Occupation } & Heavy worker (I) & 265 & $4.86 \pm 1.72$ & $<0.05$ & $41.38 \pm 16.54$ & $<0.05$ & $62.42 \pm 17.18$ & $<0.05$ \\
\hline & Office staff (II) & 248 & $4.36 \pm 1.80$ & & $36.40 \pm 17.56^{a)}$ & & $66.27 \pm 18.63^{\mathrm{a})}$ & \\
\hline & Waiter (III) & 46 & $4.18 \pm 1.82^{b)}$ & & $35.51 \pm 17.92^{b)}$ & & $69.53 \pm 26.47^{b)}$ & \\
\hline & Driver (IV) & 62 & $4.73 \pm 1.81^{e, f)}$ & & $40.69 \pm 18.83^{\mathrm{d}, \mathrm{e})}$ & & $59.70 \pm 18.65^{\mathrm{d}, \mathrm{e})}$ & \\
\hline \multirow[t]{3}{*}{ Body mass index } & Normal (I) & 324 & $4.21 \pm 1.83$ & $<0.05$ & $34.46 \pm 16.63$ & $<0.05$ & $68.19 \pm 22.50$ & $<0.05$ \\
\hline & Overweight (II) & 152 & $4.64 \pm 1.41^{\text {a) }}$ & & $40.77 \pm 14.80^{\mathrm{a})}$ & & $63.13 \pm 14.74^{\mathrm{a})}$ & \\
\hline & Obese (III) & 145 & $5.05 \pm 1.96^{b, c)}$ & & $43.93 \pm 20.62^{b)}$ & & $61.08 \pm 20.36^{b)}$ & \\
\hline \multirow[t]{3}{*}{ Duration of low back pain in last year } & 1-7 Days (I) & 98 & $4.39 \pm 1.76$ & $<0.05$ & $36.57 \pm 16.61$ & $<0.05$ & $65.81 \pm 17.31$ & $<0.05$ \\
\hline & 8-30 Days (II) & 113 & $4.79 \pm 1.81^{\mathrm{a})}$ & & $39.85 \pm 18.68$ & & $61.52 \pm 18.52^{\mathrm{a})}$ & \\
\hline & >30 Days (III) & 89 & $5.75 \pm 1.71^{b, c)}$ & & $47.23 \pm 19.21^{b, c)}$ & & $53.47 \pm 18.38^{b, c)}$ & \\
\hline
\end{tabular}

Values are presented as mean \pm standard deviation.

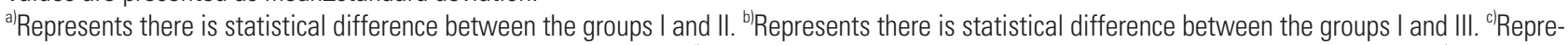
sents there is statistical difference between the groups II and III. ${ }^{d /}$ Represents there is statistical difference between the groups I and IV. ${ }^{\text {e }}$ Represents there is statistical difference between the groups II and IV. f) Represents there is statistical difference between the groups III and IV.

Table 4. Adjusted association between non-specific low back pain and independent variables in the multiple logistic regression models

\begin{tabular}{lcccc}
\multicolumn{1}{c}{ Characteristic } & Regression coefficients & Standard error & $p$-value & OR (95\% confidence interval) \\
\hline Primary school vs. middle school & 0.9936 & 0.1535 & $<0.0001$ & 2.701 (1.999-3.649) \\
\hline Primary school vs. university & 1.4420 & 0.2479 & $<0.0001$ & $4.229(2.602-6.874)$ \\
\hline Current LBP for 1-7 vs. 8-30 day & 0.6903 & 0.1547 & $<0.0001$ & $1.994(1.473-2.701)$ \\
\hline Current LBP 1-7 vs. $>30$ day & 0.8579 & 0.1587 & $<0.0001$ & $2.358(1.728-3.219)$ \\
\hline Last year LBP 0 vs. 1-7 day & 0.2766 & 0.1834 & 0.1316 & $1.319(0.920-1.889)$ \\
\hline Last year LBP 0 vs. 8-30 day & 0.6099 & 0.1741 & 0.0005 & $1.840(1.308-2.589)$ \\
\hline Last year LBP 0 vs. >30 day & 1.4898 & 0.1978 & $<0.0001$ & $4.436(3.010-6.537)$ \\
\hline Heavy worker vs. office staff & -0.0852 & 0.1819 & 0.6397 & $0.918(0.643-1.312)$ \\
\hline Heavy worker vs. waiter & 0.7190 & 0.1926 & 0.0002 & $2.052(1.407-2.994)$ \\
\hline Heavy worker vs. driver & 0.5224 & 0.3002 & 0.0818 & $1.686(0.936-3.037)$ \\
\hline Long time driving or taking a bus/subway & 0.4957 & 0.1729 & 0.0041 & $1.642(1.170-2.304)$ \\
\hline Smoking & 0.4909 & 0.1854 & 0.0081 & $1.634(1.136-2.350)$ \\
\hline Low body mass index vs. normal weight & 0.4080 & 0.2449 & 0.0957 & $1.504(0.931-2.430)$ \\
\hline Overweight vs. normal weight & 0.3875 & 0.1580 & 0.0142 & $1.473(1.081-2.008)$ \\
\hline Obese vs. normal weight & 0.8422 & 0.1665 & $<0.0001$ & $2.321(1.675-3.217)$ \\
\hline
\end{tabular}

LBP, low back pain. 


\section{Risk factors for non-specific low back pain}

Cigarette smoking in adults is constantly associated with LBP, which increases the risk of LBP among adults in a dose-dependent manner [11]. Daily consumption of $>9$ cigarettes was associated with persistent LBP [11]. A meta-analysis by Shiri et al. [12] showed that current and former smokers have a higher prevalence of LBP than non-smokers. Evidence from animal models and biologic studies indicate that smoking leads to intervertebral disc degeneration and decreased bone mineral density in the lumbar spine. While Landry et al. [13] found that tobacco consumption was not significantly associated with LBP, we found that smokers ( $\geq 10$ cigarettes/day) have more severe NSLBP than non-smokers, have a higher VAS and ODI score, and have a lower SF-36 score.

Alcohol-induced uncoordinated movements could weaken the spine, increasing its vulnerability to injuries. Additionally, excessive alcohol consumption is associated with social and psychological problems that may impact the development of chronic LBP. Yang and Haldeman [14] showed a strong relationship between LBP and current or former alcohol consumption habit. However, others showed no positive association between alcohol consumption and LBP [15]. Alcohol consumption seems to be associated with LBP only in those addicted to alcohol [15]. We found no significant correlation between alcohol consumption and severity of NSLBP.

Previous studies showed obesity or high BMI ( $>30 \mathrm{~kg} /$ $\mathrm{m}^{2}$ ) to be associated with an increased occurrence of LBP $[16,17]$. Obese individuals have a higher risk of LBP than normal weight people, and a high BMI has been significantly correlated with an increased prevalence of LBP [18]. A possible explanation is based on the increased physical loading during articulation and modifications in the gravitational axis due to increased body mass. In this investigation, we found that the patients with a higher BMI had greater pain intensity compared with that in normal weight NSLBP patients.

Exercise is widely recommended in current national and international guidelines for the treatment of chronic LBP. Henchoz and Kai-Lik So [19] found that regular sport practice was associated with a lower rate of LBP prevalence and is beneficial for primary and secondary prevention of LBP. Targeted exercises could improve muscle coordination of the spine, which is beneficial in treating LBP, and lumbar stabilization exercise is more effective than conservative treatment for improving functional disability and lumbar lordosis. However, a meta-analysis by Macedo et al. [20] found that motor control exercise had no benefit among patients with acute and sub-acute LBP. In contrast, sports activity was considered as a risk factor for LBP [21]. In this study, we evaluated the effect of general exercise on the severity of NSLBP, and the results showed that patients with regular exercising habit did not have lower pain intensity. However, several factors can affect these results such as nature of sports activity, volume, and intensity of the exercises.

Exposure to whole body mechanical vibration is now widely recognized as a cause of musculoskeletal disorders in the spinal system, particularly in occupational drivers. LBP was the most common musculoskeletal pain to be reported by drivers, and total driving distance was significantly higher in drivers with LBP [22]. This occurs because back muscles are fatigued during vibration exposure and are more prone to pain. However, Prado-León et al. [23] found no exposure-response relationship with daily hours spent working as a driver. In this study, we found that long duration of driving or traveling can increase the degree of pain intensity in LBP and ODI score and decrease SF-36 score; however, these differences were not statistically significant. One possible reason for this outcome is that those who use the subway do not experience vibration while traveling.

Many studies have focused on the relationship between heavy lifting during work and LBP $[9,24]$. However, the results are inconsistent and likely so because frequency, duration, and intensity were not considered. The intensity and frequency of lifting accurately predicts the occurrence of LBP in a dose-response relationship. In addition, the number of lifts of $\geq 25 \mathrm{~kg}$ weight during an 8 -hour working day were reported to be a significant risk factor for LBP [24]. Other studies have contradicting conclusions, conflicting findings, or no evidence of lifting as a causative factor for the occurrence of LBP [9]. We found that the patients who lifted $>10 \mathrm{~kg}$ objects in at least one quarter of their work time for $>10$ years had more serious LBP when compared with those who do not perform heavy lifting.

Modern living increases the tendency of sedentary lifestyle, which is associated with obesity and in turn is linked to chronic health problems. The disadvantage of prolonged sitting are increased intra-disc load, weakened posterior lumbar structures, and decreased metabolic exchange [25]. A previous study suggested that prolonged 
sitting is a risk factor for LBP [26]. However, the systematical study does not support the idea that prolonged sitting at work and during leisure time is related to LBP [6]. Here, we found that the patients who sit for $>8$ hours per day have more severe NSLBP.

Low educational status is associated with an increased prevalence of LBP [27]. Particularly, those with lower level of education had an approximately 4 -fold greater risk of disabling LBP when compared to those with higher level education [28]. This association may be due to exposure to tiring work postures and handling of heavy loads. Low-level education is associated with various diseases, including musculoskeletal disorders and LBP [29]. Education may impact the incidence and duration of LBP through lifestyle factors such as smoking or obesity [30]. The results in our study suggest that patients with only primary school education have higher levels of NSLBP than those who have completed secondary- or university-level education.

Studies suggest that LBP is typically recurrent, and the rates of 1-year recurrence for LBP range from $25 \%$ to $80 \%$ [31]. In this study, we evaluated the pain intensity in primary and recurrent NSLBP, and the results showed that the patients with recurrent NSLBP have a higher VAS and ODI score and lower SF-36 score. Furthermore, we evaluated the relationship between the duration of NSLBP in the last year and the pain intensity of current NSLBP; the results showed that the severity of current NSLBP increased by longer duration of last NSLBP and that the VAS and ODI scores were higher SF-36 score were lower.

\section{Strengths and weaknesses of the study}

The strengths of the present investigation are that the results are based on a large prospective cohort study and that a knowledgeable medical professional distributed and assisted the patients in filling the questionnaire. Furthermore, the response rate of our participants was $>98 \%$. A standardized definition of NSLBP was used, MRI and medical history were considered to exclude patients with organic diseases (e.g., spinal tumor and inflammatory diseases).

The current study has several limitations. For instance, the accuracy and completeness of the data within the database were dependent on the self-reported questionnaire, which may affect the internal validity of our study. Some unmeasured variables could have caused biasness, such as the patient's socio-economic status, which may relate to LBP.

\section{Conclusions}

The identification of the risk factors associated with NSLBP provides a logical rationale for the development of more effective prevention strategies, which is currently lacking. In this study, we found that the severity of NSLBP is associated with the lower level of education, poor daily living standards, heavy physical labor, long periods of driving and sitting, smoking, increased BMI, and patients with chronic NSLBP. Thus, we should avoid these risk factors to reduce the rate of NSLBP. However, more accurate prediction strategies and a better understanding of NSLBP risk factors require further investigation.

\section{Conflict of Interest}

No potential conflict of interest relevant to this article was reported.

\section{Acknowledgments}

This work was supported by grants from the National Natural Science Foundation of China (grant no., 81371984, 81401840), Sun Yat-sen University Starting Funds for Young Teachers (grant no., 16ykpy31), and GuangdongHong Kong Joint Innovation Project of Guangdong Province (2017A050506019).

\section{References}

1. Manchikanti L, Singh V, Falco FJ, Benyamin RM, Hirsch JA. Epidemiology of low back pain in adults. Neuromodulation 2014;17 Suppl 2:3-10.

2. Balague F, Mannion AF, Pellise F, Cedraschi C. Nonspecific low back pain. Lancet 2012;379:482-91.

3. Iizuka $\mathrm{Y}$, Iizuka $\mathrm{H}$, Mieda $\mathrm{T}$, et al. Prevalence of chronic nonspecific low back pain and its associated factors among middle-aged and elderly people: an analysis based on data from a musculoskeletal examination in Japan. Asian Spine J 2017;11:989-97.

4. Pakpour AH, Nikoobakht M, Campbell P. Association of pain and depression in those with chronic low back pain: the mediation effect of patient sexual functioning. Clin J Pain 2015;31:44-51.

5. Kwon MA, Shim WS, Kim MH, et al. A correlation between low back pain and associated factors: a study involving 772 patients who had undergone 
general physical examination. J Korean Med Sci 2006;21:1086-91.

6. Chen SM, Liu MF, Cook J, Bass S, Lo SK. Sedentary lifestyle as a risk factor for low back pain: a systematic review. Int Arch Occup Environ Health 2009;82:797-806.

7. Roffey DM, Wai EK, Bishop P, Kwon BK, Dagenais S. Causal assessment of occupational standing or walking and low back pain: results of a systematic review. Spine J 2010;10:262-72.

8. Roffey DM, Wai EK, Bishop P, Kwon BK, Dagenais S. Causal assessment of workplace manual handling or assisting patients and low back pain: results of a systematic review. Spine J 2010;10:639-51.

9. Wai EK, Roffey DM, Bishop P, Kwon BK, Dagenais S. Causal assessment of occupational lifting and low back pain: results of a systematic review. Spine J 2010;10:554-66.

10. Minghelli B, Oliveira R, Nunes C. Non-specific low back pain in adolescents from the south of Portugal: prevalence and associated factors. J Orthop Sci 2014;19:883-92.

11. Mikkonen P, Leino-Arjas P, Remes J, Zitting P, Taimela S, Karppinen J. Is smoking a risk factor for low back pain in adolescents?: a prospective cohort study. Spine (Phila Pa 1976) 2008;33:527-32.

12. Shiri R, Karppinen J, Leino-Arjas P, Solovieva S, Viikari-Juntura E. The association between smoking and low back pain: a meta-analysis. Am J Med 2010;123:87.e7-35.

13. Landry MD, Raman SR, Sulway C, Golightly YM, Hamdan E. Prevalence and risk factors associated with low back pain among health care providers in a Kuwait hospital. Spine (Phila Pa 1976) 2008;33:53945.

14. Yang H, Haldeman S. Behavior-related factors associated with low back pain in the US adult population. Spine (Phila Pa 1976) 2018;43:28-34.

15. Leboeuf-Yde C. Alcohol and low-back pain: a systematic literature review. J Manipulative Physiol Ther 2000;23:343-6.

16. Webb R, Brammah T, Lunt M, Urwin M, Allison T, Symmons D. Prevalence and predictors of intense, chronic, and disabling neck and back pain in the UK general population. Spine (Phila Pa 1976) 2003;28:1195-202.

17. Hershkovich O, Friedlander A, Gordon B, et al. As- sociations of body mass index and body height with low back pain in 829,791 adolescents. Am J Epidemiol 2013;178:603-9.

18. Zhang TT, Liu Z, Liu YL, Zhao JJ, Liu DW, Tian QB. Obesity as a risk factor for low back pain: a metaanalysis. Clin Spine Surg 2018;31:22-7.

19. Henchoz Y, Kai-Lik So A. Exercise and nonspecific low back pain: a literature review. Joint Bone Spine 2008;75:533-9.

20. Macedo LG, Saragiotto BT, Yamato TP, et al. Motor control exercise for acute non-specific low back pain. Cochrane Database Syst Rev 2016;2:CD012085.

21. Demblans-Dechans B, Ayrolles C, Clement JL, Lassoued S, Fournie B, Fournie A. Lumbar biomechanics and sports: spondylolysis of L5. Rev Rhum Mal Osteoartic 1988;55:405-10.

22. Noda M, Malhotra R, DeSilva V, et al. Occupational risk factors for low back pain among drivers of threewheelers in Sri Lanka. Int J Occup Environ Health 2015;21:216-24.

23. Prado-Leon LR, Aceves-Gonzalez C, Avila-Chaurand R. Occupational driving as a risk factor in low back pain: a case-control study in a Mexican population. Work 2008;31:387-96.

24. Hoogendoorn WE, Bongers PM, de Vet HC, et al. Flexion and rotation of the trunk and lifting at work are risk factors for low back pain: results of a prospective cohort study. Spine (Phila Pa 1976) 2000;25:3087-92.

25. Corlett EN. Background to sitting at work: researchbased requirements for the design of work seats. Ergonomics 2006;49:1538-46.

26. Korshoj M, Jorgensen MB, Hallman DM, LagerstedOlsen J, Holtermann A, Gupta N. Prolonged sitting at work is associated with a favorable time course of low-back pain among blue-collar workers: a prospective study in the DPhacto cohort. Scand J Work Environ Health 2018 Mar 15 [Epub]. https://doi. org/10.5271/sjweh.3726.

27. Karunanayake AL, Pathmeswaran A, Kasturiratne A, Wijeyaratne LS. Risk factors for chronic low back pain in a sample of suburban Sri Lankan adult males. Int J Rheum Dis 2013;16:203-10.

28. Schmidt CO, Moock J, Fahland RA, Feng YY, Kohlmann T. Back pain and social status among the working population: what is the association?: results from a German general population survey. Schmerz 
2011;25:306-14.

29. Schmidt CO, Raspe H, Pfingsten M, et al. Back pain in the German adult population: prevalence, severity, and sociodemographic correlates in a multiregional survey. Spine (Phila Pa 1976) 2007;32:2005-11.

30. Power C, Frank J, Hertzman C, Schierhout G, Li L. Predictors of low back pain onset in a prospective British study. Am J Public Health 2001;91:1671-8.
31. Stanton TR, Henschke N, Maher CG, Refshauge KM, Latimer J, McAuley JH. After an episode of acute low back pain, recurrence is unpredictable and not as common as previously thought. Spine (Phila $\mathrm{Pa}$ 1976) 2008;33:2923-8. 